\title{
Analyzing input quality along three dimensions: interactive, linguistic, and conceptual
}

\author{
Meredith L. ROWE* and Catherine E. SNOW \\ Harvard University Graduate School of Education, USA \\ ${ }^{*}$ Corresponding author: Harvard University - Graduate School of Education, 14 Appian Way, Cambridge, \\ Massachusetts 02138, United States. E-mail: meredith_rowe@gse.harvard.edu
}

(Received 23 September 2018; revised 13 April 2019; accepted 2 August 2019; first published online 31 October 2019)

\begin{abstract}
This paper provides an overview of the features of caregiver input that facilitate language learning across early childhood. We discuss three dimensions of input quality: interactive, linguistic, and conceptual. All three types of input features have been shown to predict children's language learning, though perhaps through somewhat different mechanisms. We argue that input best designed to promote language learning is interactionally supportive, linguistically adapted, and conceptually challenging for the child's age/level. Furthermore, input features interact across dimensions to promote learning. Some but not all qualities of input vary based on parent socioeconomic status, language, or culture, and contexts such as book-reading or pretend play generate uniquely facilitative input features. The review confirms that we know a great deal about the role of input quality in promoting children's development, but that there is much more to learn. Future research should examine input features across the boundaries of the dimensions distinguished here.
\end{abstract}

Keywords: caregiver input; linguistic complexity; semantic contingency; conversational responsiveness; decontextualized language; extended discourse

\section{Introduction}

It is broadly accepted that the language input children receive from others plays a role in their language learning. After all, young preliterate children need to hear specific words and grammatical constructions to learn those words and the rules governing those constructions, and thus it is not surprising that variations in the input children are exposed to will lead to variations in rate and breadth of learning (e.g., Huttenlocher, Waterfall, Vasilyeva, Vevea, \& Hedges, 2010). While the quantity of input certainly plays a role (e.g., Hart \& Risley, 1995; Lieven, 2010; Weisleder \& Fernald, 2013), the quality of the input is often found to matter more (e.g., Rowe, 2012). But, what is input quality? The goal of this paper is to summarize what we know from the literature to date about the specific qualities or features of caregiver input that help promote language learning across the early childhood period.

(C) Cambridge University Press 2019 
There are, of course, many studies that have made implicit claims about what quality in language input is. We synthesize these claims by offering four ideas that have not been made explicit in relation to one another in the previous literature. First, we offer a new way of conceptualizing (and potentially analyzing) input quality by specifying three dimensions of quality that have not previously been explicitly distinguished: the interactive, the linguistic, and the conceptual. Second, we discuss how these three dimensions are related to one another. Third, we take a developmental approach, recognizing that the features of input that matter most in supporting learning differ for children of different ages, and arguing that understanding those developmental differences is prerequisite to using data about input to understand the mechanisms involved in language learning. Finally, we highlight the fact that some of these input features vary by socioeconomic status, language spoken, or culture, whereas others do not, and that the interactional context plays a key role in eliciting certain types of input.

The mechanisms hypothesized to explain how caregiver input influences children's language acquisition are rooted in socio-cultural and social-interactionist theoretical perspectives (Bruner, 1981; Vygotsky, 1978), which stress the importance of children's early environments and social-communicative interactions to language development. Vygotsky's concept of the Zone of Proximal Development (ZPD) suggests that the value of any feature of parent input depends on the age and language ability of the child; input that is challenging, but not too difficult, should promote the most learning. Further, the child plays an active role in this transactional process; input that is engaging and responsive to the child's needs and interests is the most helpful. In general, the literature supports these theoretical perspectives.

Previous reviews have defined quality through analysis of two dimensions of the input: interactional and linguistic (e.g., Cartmill, 2016; Lieven, 2019). Here, we build on prior work by adding a third dimension of input quality that needs to be considered (conceptual), and by exploring the overlap among the dimensions. We argue that high quality input is characterized by: (1) interactional features such as responsiveness, shared attention, and discussions of child interests, that are maximally supportive of child involvement; (2) levels of linguistic complexity and redundancy, as reflected in phonological, lexical, and grammatical features of the input, that are well adapted to the child's developmental stage; (3) the introduction of conceptual content (topics of conversation) that offer appropriate challenge for the child's developmental level, e.g., a focus primarily on present and familiar objects and events for very young children but introduction of more abstract topics (past, present, irrealis) for older children.

A summary of the different dimensions and corresponding examples of specific input features across the period from birth to age five is displayed in Figure 1 and discussed in the sections that follow. Our review is not exhaustive, but intended to provide examples across the dimensions and across early development. By conceptualizing input quality in this way, we can see that each dimension feeds into the next. Further, we argue that all three of these dimensions are important to consider simultaneously in research on input quality, and that for optimal learning in the child each dimension would be maximized, whereas if any dimension is minimized learning may be hindered. Importantly, the specific features that fill in each dimension may differ based on culture, language spoken, or other factors found to predict input variation. 


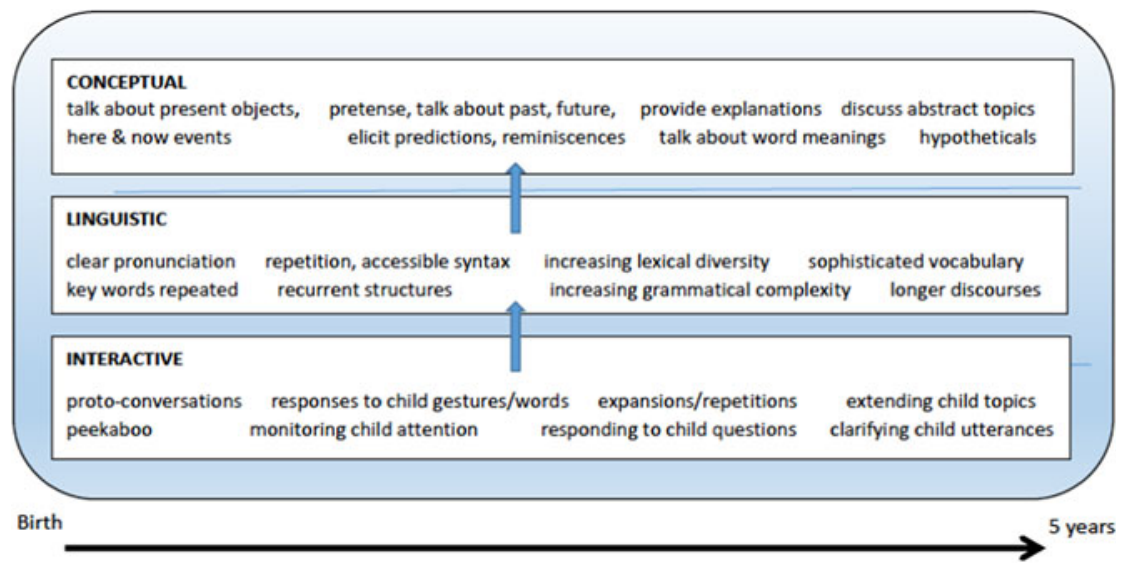

Figure 1. Examples of features of parent input that predict child vocabulary between birth and age five.

\section{Interactional features of input across early development Infancy}

Language learning is socially mediated (Kuhl, 2007), reflecting the dual facts that children are motivated to engage in interactions with other humans (e.g., Tomasello, Carpenter, Call, Behne, \& Moll, 2005) and that caregivers are good at providing useful information to babies during interactions (Kuhl, 2007). From birth, parents who more often respond contingently (and verbally) to their infants' vocalizing behaviors have children with larger vocabularies later (Donnellan, Bannard, McGillion, Slocombe, \& Matthews, 2019; Goldstein \& Schwade, 2008), likely because they socialize their children early and often into the back-and-forth nature of communication while providing informative input (Tamis-LeMonda, Kuchirko, \& Song, 2014). Parents' contingent responses to infants are found to be linguistically simpler than their non-contingent utterances, suggesting that better learning opportunities may be provided within these contingent interactions (Albert, Schwade, \& Goldstein 2017) and thus provide an example of how interactional features influence linguistic and conceptual features of input. Indeed, as children get older and more communicative themselves, parents maintain high levels of responsiveness while upping the ante for the linguistic sophistication of specific child contributions to respond to (e.g., Snow, 1972, 1977), in essence scaffolding the child into more sophisticated contributions over time.

\section{Toddlerhood}

The positive consequences of responsiveness remain as strong through the toddler period as in infancy. For example, Hirsh-Pasek and colleagues (2015) found that in a large low-income sample of families with 24-month-olds, the extent to which the parent and child engaged in a CONVERSATIONAL DUET - an interaction that was cohesive and well-balanced, with multiple connected turns per person that flowed smoothly was a better predictor of child expressive language at 36 months than the number of words parents produced in the interaction. Similarly, children's language development from 18 to 48 months was more robustly predicted by frequency of 
adult-child conversation than by quantity of adult input, or by television exposure (Zimmerman et al., 2009). Other studies suggest that the reason why language on television might not be useful is that it is not contingent (e.g., Kuhl, 2007). For example, children are able to learn novel words from a socially contingent interlocutor on a video chat system such as skype, yet they do not learn the same words from non-contingent video (O’Doherty et al., 2011; Roseberry, Hirsh-Pasek, \& Golinkoff, 2014). Similarly, overheard speech, or speech that is not directed to the child, but potentially heard by the child, in the home environment does not contribute to children's language development. In diverse samples of American families (Shneidman, Arroyo, Levine, \& Goldin-Meadow, 2013; Weisleder \& Fernald, 2013), the quantity and diversity of adult speech directed to the child in the home environment predicted child language outcomes, but the same properties of overheard speech did not. Similar findings surfaced in Mayan communities (Shneidman \& Goldin-Meadow, 2012), where a positive effect of overheard speech might be expected, as children are socialized to better attend to multiple parties at once (e.g., Rogoff, 1995). However, it is important to note that, under more controlled experimental conditions, older toddlers are able to learn words through overhearing (e.g., Akhtar, Jipson, \& Callanan, 2001). While this evidence might seem contradictory, we argue that learning through overhearing in experimental contexts may be possible because the other dimensions of input quality are maximized. That is, often in these experimental contexts, the child is overhearing a conversation that is conceptually within the child's level of understanding, and linguistically tailored to the child's level (as opposed to overhearing one's parents talking about their taxes in a home environment (e.g., Golinkoff, Hoff, Rowe, Tamis-LeMonda, \& Hirsh-Pasek, 2019)).

\section{Preschoolers}

Studies with preschool-aged children (3-5 years) tend to focus primarily on linguistic and conceptual features of the input (as discussed below); however, the small literature on interactive features with preschoolers continues to highlight the importance of engaging children in back-and-forth conversations. For example, a recent study (Romeo et al., 2018) found that the number of conversational turns between parents and their four-year-olds at home was a significant positive predictor of children's brain processing during an fMRI language task as well as their abilities on standardized tests of vocabulary and syntax. Moreover, the effect of conversational turns on the battery of language assessments was statistically mediated by language processing in the fMRI task. This suggests that engaging in more conversations may enhance children's ability to process language on-line, which could serve to build their oral language skills. Importantly, the overall quantity of parent talk or child talk did not relate to brain or behavioral outcomes, indicating that the effect on language processing and skill is due to interactivity rather than simple exposure. Similarly, Dickinson and Smith (1994) found that amount of childinvolved talk during preschool book-reading sessions predicted children's gains on vocabulary and narrative comprehension better than other features of teacher talk.

In sum, socializing children from early on into back-and-forth communicative exchanges supports learning, and there is no evidence that the value of adult responsiveness to child communicative initiations declines with age. Advice to parents and practitioners often endorses the value of 'serve and return' (Shonkoff \& Bales, 2011). We argue that serve-and return is only a start, that what is really 
helpful is longer and longer volleys back and forth between a child and her caregiver. That is, looking across the dimensions of input quality proposed here, if interactive responsiveness is to feed into the linguistic and conceptual development one hopes for, then simple returns are not enough. Children need to engage in more extended discourse that displays both increasing linguistic sophistication and conceptual challenge with age. That engagement is possible only if there is consistent access to supportive interactions with adults.

\section{Linguistic features of input across early development Infancy}

Infant-Directed Speech (IDS), or the specialized speech register adults tend to use when speaking to babies, is found to support language learning. IDS is characterized by shorter utterances with exaggerated intonation (Fernald, 1989) and vowel modification (Bernstein Ratner, 1984). There have been several recent reviews of the relations between these IDS features and infant language learning (e.g., Golinkoff, Can, Soderstrom, \& Hirsh-Pasek, 2015; Soderstrom, 2007). Thus, here we review just a few findings in this area that highlight how the interactive and linguistic dimensions of input quality interact to promote language learning. For example, it has been argued that infants prefer to listen to IDS over ADS (adult-directed speech) because the linguistic features of exaggerated intonation, phonological clarity, lexical repetition, and grammatical simplicity make it easier for infants to attend to IDS (e.g., Soderstrom, 2007). Indeed, infants show more brain activation when listening to IDS vs. ADS (Saito et al., 2007). This is a clear example of how supportive interactions make possible the adaptation of linguistic features to child language levels. More recent evidence is confirming that IDS is not only preferred by infants, but also that individual differences in IDS across mothers predict language outcomes. For example, Hartman, Bernstein Ratner, and Newman (2017) found that the size of a mother's vowel space in speech to toddlers predicted the children's receptive and expressive language skills 6 months later. These individual differences emerged even though vowel space is consistently expanded in IDS over ADS. Furthermore, a recent intervention study (Ferjan-Ramirez, Lytle, Fish, \& Kuhl, 2019) provides some evidence that these links between parental use of adapted IDS features and child language learning may be causal. Parents were coached to talk more and specifically to use more 'parentese' - infant-directed speech with high pitch, slow tempo, and exaggerated contours - with their 6- to 14-month-olds. The parents who received coaching talked more to their children, a larger proportion of their utterances were produced in parentese, and their children showed steeper improvements in their babbling across the intervention period and larger vocabularies at 14 months. Prosodic features support infants' ability to segment speech into grammatical units more effectively when listening to IDS than to ADS, potentially simplifying access to syntax.

When interacting with infants and toddlers, parents repeat lexical items more than when interacting with older children or adults (e.g., Snow, 1972), and repetition of vocabulary words with infants is a feature of input that predicts vocabulary learning. For example, Newman, Rowe, and Bernstein Ratner (2016) examined a variety of input measures during a parent-child interaction when the child was 7 months in relation to children's vocabulary at age two. They found that it was not the quantity (word tokens) or diversity (word types) of parent speech that predicted the children's vocabulary outcomes, but the type-token ratio; in other words, parents who produced fewer 
different words and thus were repeating words more frequently had children with larger vocabularies later. Thus, lexical repetition in the input to infants may promote learning, but this relationship flips as children get older.

\section{Toddlerhood}

Toddlers, in contrast, are developing rapidly in their own language and cognitive skills and can handle and benefit from input that is linguistically more sophisticated than infants. Research finds that using a diverse range of vocabulary words with toddlers, including lower-frequency vocabulary words, predicts vocabulary growth (e.g., Huttenlocher et al., 2010; Pan, Rowe, Singer, \& Snow, 2005) and later vocabulary size, over and above the quantity of speech (Rowe, 2012). Similarly, a recent study found that the diversity, not the quantity, of verbs used with 21-month-olds predicts the children's verb production six months later, even with child 21-month vocabulary controlled (Hsu, Hadley, \& Rispoli, 2017). Other input features used with two-year-olds that correlate with later vocabulary development and skill include the use of wh-questions (Rowe, Leech, \& Cabrera, 2017) and the use of longer, more complex utterances (Hoff, 2003). Several studies show that both the frequency and the diversity of sentence frames in which specific verbs appear predict the acquisition of those verbs in children's speech (de Villiers, 1984; Naigles \& Hoff-Ginsberg, 1998). In addition, more global measures of clausal and constituent diversity (i.e., variation in ways of combining clauses and uses of a variety of elements within clauses) in parent input from 14 to 46 months predict growth in the same measures of children's own syntactic development (Huttenlocher et al., 2010). Some causal evidence of input quality effects in this area come from a recent parent intervention designed to increase children's grammatical development by training parents to increase the diversity of grammatical subjects in their speech (Hadley et al., 2017). The theory is that more exposure to diverse third person lexical noun phrases (e.g., your toy, the baby) will aid in children's representation of subject-predicate relations and help them to produce more diverse subject-verb combinations themselves. The treatment resulted in an increase in parents' lexical noun phrase (NP) subject tokens and types compared to a control group, and parents' lexical NP subject types in turn predicted children's sentence diversity growth from 21 to 30 months. For the current argument about dimensions of quality in input, it is worth highlighting that this intervention focused on increasing the specific linguistic input measures discussed, but also emphasized the importance of back-and-forth conversations (Hadley et al., 2017).

\section{Preschoolers}

Using a diverse and sophisticated vocabulary with children continues to be effective in promoting vocabulary of somewhat older children (Weizman \& Snow, 2001). Exposure to more complex syntax can be helpful in promoting syntactic comprehension at this age as well. For example, in a sample of children aged 54 to 60 months the proportion of complex sentences in parent speech was significantly positively correlated with the proportion of complex sentences in child speech at home and school (Huttenlocher, Vasilyeva, Cymmerman, \& Levine, 2002). Furthermore, the syntactic complexity of teacher speech predicted children's growth in syntactic comprehension over a preschool year (Huttenlocher et al., 2002). In a separate study with preschool children, Vasilyeva, Waterfall, and Huttenlocher (2006) 
experimentally manipulated the frequency of passive voice in stories read to four-year-olds. They found that children who heard stories with more passive sentences produced more passive constructions and scored better on a passive comprehension measure than children who heard the stories with only active sentences. These results provide some additional causal evidence that syntactic complexity of the input relates to child learning.

Evidence that greater linguistic complexity in the input promotes preschoolers' language development also comes from studies of book-sharing interactions, during which adults speak more complexly than during either oral story-telling or casual conversations (Weizman \& Snow, 2001). Book-sharing frequency shows a strong relation to children's vocabulary growth (e.g., Wasik \& Hindman, 2014), as well as to measures of grammatical development (Isbell, Sobol, Lindauer, \& Lowrance, 2004; Noble, Cameron-Faulkner, \& Lieven, 2018; Senechal, Pagan, Lever, \& Quelette, 2008) in naturalistic studies of parent-child interaction, a relationship confirmed in one intervention study conducted in a preschool classroom (Rezzonico et al., 2015).

\section{Conceptually supportive features Infancy}

Another dimension of variability in adult talk to children is the extent to which the focus of the talk is grounded in the here and now versus being more abstract and distant. While talk about concrete and visible referents is clearly helpful to very young learners, older learners benefit from more conceptually challenging talk. During infancy and the early toddler period, hearing a lot of talk is clearly important (e.g., Huttenlocher, Haight, Bryk, Seltzer, \& Lyons, 1991; Rowe, 2012); however, talk that is grounded in the here and now and takes advantage of the child's focus of attention tends to be most useful. We argue that such contingent talk should be analyzed as conceptually supportive input in infancy. For example, 18 -month-olds are more likely to learn the name of an object that is labeled while it is the dominant object in that child's view (Yu \& Smith, 2012). Similarly, the literature on facilitative features in cross-situational word learning highlights the connection between the linguistic and conceptual levels of input quality: parents who more consistently make clear what they are referring to in language with 14- to 18-month-olds have children who learn words faster (Cartmill et al., 2013). For example, within joint attention episodes at 15 months, frequency of maternal talk about objects the child was already focused on was correlated with vocabulary at 21 months, whereas maternal redirecting talk was negatively correlated with later vocabulary (Tomasello \& Farrar, 1986). However, not all redirecting talk is created equal. Shimpi and Huttenlocher (2007) distinguished successful redirecting labels, or those that resulted in directing the child's attention to the labeled object, versus unsuccessful redirecting labels. They found positive relations between parents' use of successful redirecting labels and children's vocabulary, whereas associations between vocabulary and unsuccessful redirects were negative. They also found an association between use of gesture and successful redirecting. Thus, gesture is one way that caregivers can make the objects of discussion more salient and aid in comprehension. Indeed, parents who use gesture to refer to a larger variety of objects when interacting with 14-month-olds have children who gesture more themselves and who also have larger vocabularies several years later (Rowe \& Goldin-Meadow, 
2009). Similarly, talk mediated by picture-books has been implicated in supporting language acquisition; for infants, such books ideally offer one single, simple picture per page, eliciting nouns and shorter utterances (compared to toy play), ensuring a conceptual match between child attention and input (Choi, 2000; Moerk, 1985; Salo, Rowe, Leech, \& Cabrera, 2016). Thus, during infancy, frequent verbal interactions that target children's focus of attention and help children understand what is being spoken about help promote language learning.

\section{Toddlerhood}

As children get older they can handle more challenging books and conversations, on topics that are more abstract and removed from the here and now. Abstractness can be introduced through the choice of more complex topics (for example, reading The Very Hungry Caterpillar to discuss metamorphosis rather than the array of foods the caterpillar ate), through talk about future or past events, through talk about hypotheticals and counterfactuals (Who would walk the dog if we got one? What would have happened if daddy had lost his keys?), and through pretense. Frequency of engaging toddlers in pretend play predicts language development (e.g., Tamis-LeMonda \& Bornstein, 1994), and it is argued that engaging in pretense with adult support may be particularly helpful because the adult can scaffold the child to access the play themes despite their abstractness (e.g., Weisberg, Zosh, Hirsh-Pasek, \& Golinkoff, 2013). This finding emphasizes how the different dimensions of input can work together to support learning, with challenging pretense at the conceptual level being supported by high responsiveness on the interactive dimension and limitations on the complexity at the linguistic level.

Starting when children are around 30 months, the amount that parents use decontextualized language, such as talking about past or future events, or providing causal explanations about how things work in the world, is a better predictor of kindergarten vocabulary skill than is the total amount of parent talk (Rowe, 2012). Further, parents who use more decontextualized language with toddlers, not surprisingly have toddlers who use more decontextualized language with parents (Demir, Rowe, Heller, Goldin-Meadow, \& Levine, 2015), and the amount of decontextualized language parents and toddlers use in the home predicts the children's academic language skills when they are adolescents (Uccelli, Demir-Lira, Rowe, Levine, \& Goldin-Meadow, 2019). Decontextualized talk is likely helpful for conceptual reasons, as it challenges children to communicate about topics that are not grounded in the here and now, but also because it tends to be more linguistically complex than input that is contextualized (Demir et al., 2015), again highlighting how the conceptual and linguistic dimensions feed into one another.

\section{Preschoolers}

Decontextualized language experience continues to support children's language skills throughout the preschool years. As noted above, explanations can be a useful form of input because they tend to be syntactically complex, but also because they may encourage continued back-and-forth conversations between parents and children. For example, Frazier, Gelman, and Wellman (2009) found that two- to five-year-old children who asked information-seeking 'how' and 'why' questions were significantly more likely to ask a follow-up question and keep the interesting conversation going 
if they received an explanation from their caregiver as the first response. This finding exemplifies how interactive features (RESPONDING to a child's question) generate desirable linguistic features (syntactically complex explanations using cause and effect language) as well as conceptual features (discussion about abstract/unobservable topics) to promote language acquisition and knowledge acquisition simultaneously. Furthermore, having more extended discussions about the past with preschool-aged children can be helpful. For example, a growing number of studies suggest that parents who use an elaborative reminiscing style when discussing past events with their preschoolers have children whose language comprehension skills are more advanced, whose narratives are more detailed, and whose autobiographical memories are more elaborated (e.g., Peterson, Jesso, \& McCabe, 1999; Reese, Leyva, Sparks, \& Grolnick, 2010; Reese \& Newcombe, 2007).

The rich and varied literature on interactive book-reading offers another source of evidence that conceptual challenge in adult speech promotes children's development of language skills as well as expanding their domains of knowledge. Though there is mixed evidence concerning the effects of book-reading on children's narrative skills (see Senechal, 2017, for a review), some studies have found that indicators of narrative sophistication - the number of story components included, the completeness of the narrative structure - was related to exposure to interactive book-reading (Kuchirko, Tamis-LeMonda, Luo, \& Liang, 2016; Lever \& Senechal, 2011).

The conceptual affordances of book-reading are emphasized by findings that parentchild book reading contributes to children's understanding of psychological causality and others' emotions and intentions (see Dowdall et al., 2019, for a review). For example, shared reading contributes to the development of perspective-taking (understanding that another's view of a situation may be different from one's own) (e.g., Beazidou, Botsoglou, \& Vlachou, 2013; LaForge, Perron, Roy-Charland, Roy, \& Carignan, 2018; Martucci, 2016), presumably because it is an occasion for discourse about characters' internal states and emotional reactions to events (Adrian, Clemente, Villanueva, \& Rieffe, 2005; Aram, Fine, \& Ziv, 2013; Howe \& Rinaldi, 2004; Ruffman, Slade, \& Crowe, 2002; Zevenbergen, Whitehurst, \& Zevenbergen, 2003). Perspective-taking is itself key to the effective use of linguistic (e.g., deixis) as well as pragmatic (e.g., rhetorical) features of language.

The importance of active engagement by the child, i.e., attention to the interaction dimension, in producing positive effects from shared book-reading has been confirmed by Kang, Kim, and Pan (2009) and Malin, Cabrera, and Rowe (2014) studying parentchild interactions, and by both Schick (2015) and Gamez, Gonzalez, and Urbin (2016) studying teacher-child interactions in the preschool classroom. Again, we emphasize the relationships among these three dimensions - high interactivity both engages the child and supports producing language at the appropriate linguistic level, while conceptual challenge (supported for example by the content of appropriate books) helps children develop the more sophisticated cognitive and linguistic skills they will need in school.

\section{A developmental perspective}

We hope that this discussion has conveyed how essential the child's age and/or language ability is in determining the effectiveness of specific input features. The literature supports our application of the Zone of Proximal Development perspective, where 
input that is challenging, but not too challenging for a child of a given age/ability, is the most useful (see Figure 1). Therefore, input features that are helpful at one point in development might not be helpful at another. For example, on the linguistic dimension, repetition of words with infants predicted vocabulary learning, yet vocabulary diversity and sophistication (and not repetition) predicted learning in older children (e.g., Schwab, Rowe, Cabrera, \& Lew-Williams, 2018). Similarly, on the conceptual level, talk that is grounded in the here and now and refers to what is going on in the child's environment is the most useful for language learning in infancy, whereas with preschoolers a higher ratio of talk about abstract topics, those that go beyond the here and now, to contextualized talk is found to predict learning.

Along the interactional dimension the literature highlights the importance of engaging children in back-and-forth conversations from birth to age five (and beyond). Thus, here, what changes over development is primarily the ways that caregivers can promote those conversations, from viewing an infants' gesture as a turn in a conversation that can be responded to, to asking an older child how a character in a book is feeling, and responding to children's requests for information or explanations. The overlapping nature of the dimensions of input quality suggests that, as children increase in language ability, the conversations they engage in should increase in linguistic sophistication and conceptual challenge.

\section{The role of culture, language-specific forms, socioeconomic status, and context}

We want to highlight that the specific input features discussed so far have been primarily, but not exclusively, based on research with children in Western societies learning English. We do not claim that these specific features will be used or would support learning in all cultures and contexts. Cultural differences are certainly evident on all of the dimensions of input quality. At the interactional level, Richman, Miller, and LeVine (1992) found that the Gusii of Kenya were significantly less verbally responsive to their children's vocalizations than were mothers in suburban Boston. At the linguistic level, some languages have an extensive 'baby talk' lexicon and widespread use of diminutives with young children, whereas the Kaluli of Papua New Guinea, for example, prohibit such adaptations (Schieffelin, 1990). At the conceptual level, Chinese parents are found to use personal story-telling (reminiscing about the past and in particular their children's previous behaviors) with their 30-month-olds to convey moral and social standards, whereas American parents engaged their toddlers in story-telling about the past for entertainment or affirmation purposes (Miller, Wiley, Fung, \& Liang, 1997). Norwegian parents both ask for and recount personal events more than American parents, who more frequently request and provide explanations (Aukrust \& Snow, 1998). These differences have implications. For example, if in a particular culture children should not ask adults questions, then certain forms of linguistic and conceptual expansion might not occur. Further, the exposure and socialization to certain features of input over others may influence how children learn. For example, children who are exposed to more attention-directing rather than attention-following talk may have advantages in learning from being told what to do rather than being able to initiate conversational topics (e.g., Vigil, 2002).

One impact of input on acquisition derives more directly from the language being learned itself than from adult use of it; this is the relative frequency of various forms in the input, and their capacity to predict order of acquisition (e.g., Lieven, 2010). 
For example, the learning of specific past tense forms in English is well predicted by the frequency of those forms in adult speech (Matthews \& Theakston, 2006), and children's more frequent provision of tense marking on auxiliary BE than on copula BE or third person singular may well be related to the relative frequency of those forms in the input (Pine, Conti-Ramsden, Joseph, Lieven, \& Serratrice, 2008). Similarly, Finnish children's error rate in person/number marking on verbs was higher for low-frequency person/ number contexts, and often involved substituting more frequent forms (Räsänen, Ambridge, \& Pine, 2016).

In addition to raw frequencies, though, other aspects of the way adults deploy those forms may explain patterns of acquisition. For example, German-speaking children aged two to three years omit the interrogative word was 'what' more frequently than other initial interrogative words, perhaps because the initial was is much less likely to be stressed than the other words (Schmerse, Lieven, \& Tomasello, 2013). The influence of frequency of various grammatical forms on likelihood of acquisition also highlights one domain in which quantity of input might play a role in predicting learning.

Within cultures, it is also important to consider how some features of input within each dimension may, or may not, vary by parent socioeconomic status (SES). For example, in a socioeconomically diverse sample of families from the greater Chicago area, Rowe (2012) found that parent education (a core component of SES) was significantly, positively correlated with the diversity and sophistication of parents' vocabulary and with the number of pretend utterances parents used with their 30-month-olds. However, parent narrative utterances (about the past and the future) remained unassociated with SES across all child ages (18, 30, and 42 months), suggesting that parents with all levels of schooling may be equally likely to engage their children in talk about the past and the future.

Significant variation in input features is also found within samples that are homogeneous in SES. For example, Hirsh-Pasek and colleagues (2015) found extensive variation in the incidence of CONVERSATIONAL DUETS in their large, entirely low-income national sample of parents and two-year-olds. Pan and colleagues (2005) found variability in mothers' use of pointing and vocabulary diversity (word types) that predicted child vocabulary growth, in an entirely low-income sample of over 100 parents in southern Vermont. These and other studies focused on specific SES groups highlight the large variability across caregivers in the input they provide, and suggest that, within cultures and languages spoken, important factors in addition to SES contribute to how caregivers communicate with their children along the three dimensions discussed here (see Rowe, 2018, for a review of some of these factors).

Finally, it is also important to note that specific contexts elicit different types of parent input. For example, book-reading is an ideal way to bring new, lower-frequency lexical items and more remote topics into the conversation. Parents typically ask more wh-questions and use more diverse vocabulary during book-reading than toy play (Hoff, 2010; Salo et al., 2016), but books may also be used as a context for discussing abstract or distant topics in some families and classrooms. In family interactions, decontextualized language tends to occur more often during mealtimes or other situations when there is not an object of attention like a toy or book present (e.g., Dickinson \& Tabors, 2001). These context effects are important to consider in research studies that examine input across different ecological contexts, but also for intervention studies that may aim to promote certain types of input. 


\section{A call to examine input quality effects across these dimensions}

This review of language input is the first to make a clear distinction among three levels of analysis of the input, and the first to reinterpret prior work by sorting out not just whether researchers were focusing on interactional, linguistic, or conceptual features, but also how those three sets of features were differentially related to outcomes. The failure to distinguish clearly among the three dimensions in previous research reflects to some extent their inter-connections, which we will explore and exemplify in this section of the review.

In 1977, Toni Cross introduced the term 'semantic contingency' to characterize what she considered a feature of optimal adult input to young children. Semantic contingency (implicitly) operated at two of the levels we distinguish here: semantically contingent talk was conversationally responsive to child utterances, but also conceptually related to those utterances. Similarly, the large body of work focused on expansions and recasts, starting with Brown and Bellugi (1964) and extended both descriptively and experimentally by Keith Nelson and colleagues (e.g., Clarke, Soto, \& Nelson, 2017; Nelson, 1977; Nelson, Camarata, \& Camarata, 1996) among others (e.g., Demetras, Post, \& Snow, 1986), required analysis of both interactional (expansions/recasts are conversational responses) and linguistic features (they expand or correct the linguistic form used by the child).

We argue as well that the large body of work on the value of shared book-reading for promoting child language could be re-examined through the trifocal lens of interaction, language, and concepts. In 1978, Ninio and Bruner documented the conversational scaffold established by the mother of a preverbal boy in the course of reading picture-books with him. Her repetition of 'what's that?' and 'where's the ... ?' inducted him into a conversational exchange that was initially largely language- and concept-free. He started to introduce gestures and proto-words at appropriate points in the exchange, and these responses slowly acquired more credibility as intentional communicative acts-points and words. The presence of the book supported conceptual growth by ensuring clarity of the referent. The mother's modeling of the target response supported development of morphology and lexical reference. The predictable interactive context enabled the child to participate in productive ways from a very early age.

Studies of slightly older children engaged in book-reading with adults document cases where turn-taking interactions support child repetition of adult utterances, often with limited evidence of conceptual growth at first (e.g., Snow \& Goldfield, 1982, 1983). Early book-reading interactions may function more like games, in which children simply learn to take their turns, than like opportunities for exchange of semantic content. Of course, somewhat older children who have experienced repeated and dialogic readings (Whitehurst et al., 1988) of age-appropriate books are exposed to conceptually challenging input in contexts that enable them to process it and to learn the linguistic skills needed to discuss the book topics (Senechal; Dickinson; reviewed in Mol, Bus, De Jong, \& Smeets, 2008).

In sum, the quality of caregiver input matters for child language development, but cannot be analyzed on a single dimension. The features of input that play a role differ on interactional, linguistic, and conceptual dimensions as well as in ways that reflect the age and language abilities of the child. Thus, across early childhood, it is helpful for children to hear a lot of talk, but even more helpful if that talk is 
responsive and engaging as well as linguistically adapted to the child's level and conceptually challenging; both adaptation and challenge depend entirely on the developmental level of the child. It would be helpful for the field of child language development if studies of input quality systematically distinguished interactive, linguistic, and conceptual features, to make clearer the sources of positive effects on learning as well as the mechanisms that might explain those effects.

\section{References}

Adrian, J., Clemente, R., Villanueva, L., \& Rieffe, C. (2005). Parent-child picture-book reading, mothers' mental state language and children's theory of mind. Journal of Child Language, 32, 673-86.

Akhtar, N., Jipson, J., \& Callanan, M. A. (2001). Learning words through overhearing. Child Development, 72(2), 416-30.

Albert, R. R., Schwade, J. A., \& Goldstein, M. H. (2017). The social functions of babbling: acoustic and contextual characteristics that facilitate maternal responsiveness. Developmental Science, e12641.

Aram, D., Fine, Y., \& Ziv, M. (2013). Enhancing parent-child shared book reading interactions: promoting references to the books' plot and socio-cognitive themes. Early Childhood Research Quarterly, 28, 111-22.

Aukrust, V. G., \& Snow, C. E. (1998). Narratives and explanations in Norwegian and American mealtime conversations. Language in Society, 27, 221-46.

Beazidou, E., Botsoglou, K., \& Vlachou, M. (2013). Promoting emotional knowledge: strategies that Greek preschool teachers employ during book reading. Early Child Development and Care, 183, 613-26.

Bernstein Ratner, N. (1984). Patterns of vowel modification in mother-child speech. Journal of Child Language, 11(3), 557-78.

Brown, R., \& Bellugi, U. (1964). Three processes in the child's acquisition of syntax. Harvard Educational Review, 34(2), 133-51.

Bruner, J. S. (1981). The social context of language acquisition. Language \& Communication, 1(2/3), 155-78.

Cartmill, E. A. (2016). Mind the gap: assessing and addressing the word gap in early education. Policy Insights from the Behavioral and Brain Sciences, 3(2), 185-93.

Cartmill, E. A., Armstrong, B. F., Gleitman, L. R., Goldin-Meadow, S., Medina, T. N., \& Trueswell, J. C. (2013). Quality of early parent input predicts child vocabulary 3 years later. Proceedings of the National Academy of Sciences, 110(28), 11278-83.

Choi, S. (2000). Caregiver input in English and Korean: use of nouns and verbs in book-reading and toy-play contexts. Journal of Child Language, 27(1), 69-96.

Clarke, M., Soto, G., \& Nelson, K. (2017). Language learning, recasts, and interaction involving AAC: background and potential for intervention. Augmentative and Alternative Communication, 33, 42-50.

Cross, T. G. (1977). Mothers' speech adjustments: the contribution of selected child listener variables. In C. Snow \& C. Ferguson (Eds.), Talking to children (pp 151-88). Cambridge University Press.

de Villiers, J. (1984). Learning how to use verbs: lexical coding and the influence of the input. Journal of Child Language 12, 587-95.

Demetras, M., Post, K., \& Snow, C. E. (1986). Feedback to first language learners: the role of repetitions and clarification questions. Journal of Child Language, 13, 275-92.

Demir, Ö. E., Rowe, M. L., Heller, G., Goldin-Meadow, S., \& Levine, S. C. (2015). Vocabulary, syntax, and narrative development in typically developing children and children with early unilateral brain injury: early parental talk about the 'there-and-then' matters. Developmental Psychology, 51(2), 161-75.

Dickinson, D., \& Smith, M. (1994). Long-term effects of preschool teachers' book readings on low-income children's vocabulary and story comprehension. Reading Research Quarterly, 29, 104-22.

Dickinson, D. K., \& Tabors, P. O. (2001). Beginning literacy with language: young children learning at home and school. Baltimore, MD: Paul H Brookes Publishing.

Donnellan, E., Bannard, C., McGillion, M. L., Slocombe, K. E., \& Matthews, D. (2019). Infants' intentionally communicative vocalizations elicit responses from caregivers and are the best predictors of the transition to language: a longitudinal investigation of infants' vocalizations, gestures and word production. Developmental Science, e12843. 
Dowdall, N., Melendez-Torres, G. J., Murray, L., Gardner, F., Hartford, L., \& Cooper, P. J. (2019). Shared picture book reading interventions for child language development: a systematic review and meta-analysis. Child Development, e13225.

Ferjan-Ramirez, N., Lytle, S., Fish, M., \& Kuhl, P. (2019) Parent coaching at 6 and 10 months improves language outcomes at 14 months: a randomized controlled trial. Developmental Science, e12762.

Fernald, A. (1989). Intonation and communicative intent in mothers' speech to infants: Is the melody the message? Child Development, 60(6), 1497-510.

Frazier, B. N., Gelman, S. A., \& Wellman, H. M. (2009). Preschoolers' search for explanatory information within adult-child conversation. Child Development, 80(6), 1592-611.

Gamez, P., Gonzalez, D., \& Urbin, L. (2016). Shared book reading and English learners' narrative production and comprehension. Reading Research Quarterly, 52, 275-90.

Goldstein, M. H., \& Schwade, J. A. (2008). Social feedback to infants' babbling facilitates rapid phonological learning. Psychological Science, 19(5), 515-23.

Golinkoff, E. M., Hoff, E., Rowe, M. L., Tamis-LeMonda, C. S., \& Hirsh-Pasek, K. (2019). Language matters: denying the existence of the 30-million-word gap has serious consequences. Child Development, 90(3), 985-92.

Golinkoff, R. M., Can, D. D., Soderstrom, M., \& Hirsh-Pasek, K. (2015). (Baby) talk to me: the social context of infant-directed speech and its effects on early language acquisition. Current Directions in Psychological Science, 24(5), 339-44.

Hadley, P. A., Rispoli, M., Holt, J. K., Papastratakos, T., Hsu, N., Kubalanza, M., \& McKenna, M. M. (2017). Input subject diversity enhances early grammatical growth: evidence from a parent-implemented intervention. Language Learning and Development, 13(1), 54-79.

Hart, B., \& Risley, T. R. (1995). Meaningful differences in the everyday experience of young American children. Baltimore, MD: Paul H Brookes Publishing.

Hartman, K. M., Bernstein Ratner, N. B., \& Newman, R. S. (2017). Infant-directed speech (IDS) vowel clarity and child language outcomes. Journal of Child Language, 44(5), 1140-62.

Hirsh-Pasek, K., Adamson, L. B., Bakeman, R., Owen, M. T., Golinkoff, R. M., Pace, A., ... \& Suma, K. (2015). The contribution of early communication quality to low-income children's language success. Psychological Science, 26(7), 1071-83.

Hoff, E. (2003). The specificity of environmental influence: socioeconomic status affects early vocabulary development via maternal speech. Child Development, 74(5), 1368-78.

Hoff, E. (2010). Context effects on young children's language use: the influence of conversational setting and partner. First Language, 30(3/4), 461-72.

Howe, N., \& Rinaldi, C. (2004). 'You be the big sister': maternal-preschooler internal state discourse, perspective-taking, and sibling caretaking. Infant and Child Development, 13, 217-34.

Hsu, N., Hadley, P. A., \& Rispoli, M. (2017). Diversity matters: parent input predicts toddler verb production. Journal of Child Language, 44(1), 63-86.

Huttenlocher, J., Haight, W., Bryk, A., Seltzer, M., \& Lyons, T. (1991). Early vocabulary growth: relation to language input and gender. Developmental Psychology, 27(2), 236-48.

Huttenlocher, J., Vasilyeva, M., Cymerman, E., \& Levine, S. (2002). Language input and child syntax. Cognitive Psychology, 45(3), 337-74.

Huttenlocher, J., Waterfall, H., Vasilyeva, M., Vevea, J., \& Hedges, L. V. (2010). Sources of variability in children's language growth. Cognitive Psychology, 61(4), 343-65.

Isbell, R., Sobol, J., Lindauer, L., \& Lowrance, A. (2004). The effects of storytelling and story reading on the oral language complexity and story comprehension of young children. Early Childhood Education Journal, 32, 157-63.

Kang, J., Kim, Y.-S., \& Pan, B. (2009). Five-year-olds' book talk and story telling: contributions of mother-child joint bookreading. First Language, 29, 243-65.

Kuchirko, Y., Tamis-Lemonda, C., Luo, R., \& Liang, E. (2016). 'What happened next?' Developmental changes in mothers' questions to children. Journal of Early Childhood Literacy, 16, 498-521.

Kuhl, P. K. (2007). Is speech learning 'gated' by the social brain? Developmental Science, 10(1), 110-20.

LaForge, C., Perron, M., Roy-Charland, A., Roy, E. M., \& Carignan, I. (2018). Contributing to children's early comprehension of emotions: a picture book approach. Canadian Journal of Education, 41(1), 301-28.

Lever, R., \& Senechal, M. (2011). Discussing stories: on how a dialogic reading intervention improve kindergartners' oral narrative construction. Journal of Experimental Psychology, 108, 1-24. 
Lieven, E. (2010). Input and first language acquisition: evaluating the role of frequency. Lingua, 120(11), 2546-56.

Lieven, E. (2019). Input, interaction, and learning in early language development. In V. Grover, P. Uccelli, M. L. Rowe, \& E. Lieven (Eds.), Learning through language: towards an educationally informed theory of language learning (pp. 19-30). Cambridge University Press.

Malin, J. L., Cabrera, N. J., \& Rowe, M. L. (2014). Low-income minority mothers' and fathers' reading and children's interest: longitudinal contributions to children's receptive vocabulary skills. Early Childhood Research Quarterly, 29(4), 425-32.

Martucci, K. (2016). Shared storybook reading in the preschool setting and considerations for young children's theory of mind. Journal of Early Childhood Research, 14, 55-68.

Matthews, D. E., \& Theakston, A. L. (2006). Errors of omission in English-speaking children's production of plurals and the past tense: the effects of frequency, phonology, and competition. Cognitive Science, 30 (6), 1027-52.

Miller, P. J., Wiley, A. R., Fung, H., \& Liang, C. H. (1997). Personal storytelling as a medium of socialization in Chinese and American families. Child Development, 68(3), 557-68.

Moerk, E. L. (1985). Picture-book reading by mothers and young children and its impact upon language development. Journal of Pragmatics, 9(4), 547-66.

Mol, S. E., Bus, A. G., De Jong, M. T., \& Smeets, D. J. (2008). Added value of dialogic parent-child book readings: a meta-analysis. Early Education and Development, 19(1), 7-26.

Naigles, L. R., \& Hoff-Ginsberg, E. (1998). Why are some verbs learned before other verbs? Effects of input frequency and structure on children's early verb use. Journal of Child Language 25, 95-120.

Nelson, D. G. K., Hirsh-Pasek, K., Jusczyk, P. W., \& Cassidy, K. W. (1989). How the prosodic cues in motherese might assist language learning. Journal of Child Language, 16(1), 55-68.

Nelson, K. E. (1977). Facilitating children's syntax acquisition. Developmental Psychology, 13, 101-7.

Nelson, K. E., Camarata, S. M., \& Camarata, M. (1996). Effects of imitative and conversational recasting treatment on the acquisition of grammar in children with specific language impairment and younger language normal children. Journal of Speech, Language, and Hearing Research, 39, 850-9.

Newman, R. S., Rowe, M. L., \& Bernstein Ratner, N. (2016). Input and uptake at 7 months predicts toddler vocabulary: the role of child-directed speech and infant processing skills in language development. Journal of Child Language, 43(5), 1158-73.

Ninio, A., \& Bruner, J. (1978) The achievements and antecedents of labelling. Journal of Child Language, $5,1-15$.

Noble, C., Cameron- Faulkner, T., \& Lieven, E. (2018). Keeping it simple: the grammatical properties of shared book reading. Journal of Child Language, 45, 753-66.

O’Doherty, K., Troseth, G. L., Shimpi, P. M., Goldenberg, E., Akhtar, N., \& Saylor, M. M. (2011). Third-party social interaction and word learning from video. Child Development, 82(3), 902-15.

Pan, B. A., Rowe, M. L., Singer, J. D., \& Snow, C. E. (2005). Maternal correlates of growth in toddler vocabulary production in low-income families. Child Development, 76(4), 763-82.

Peterson, C., Jesso, B., \& McCabe, A. (1999). Encouraging narratives in preschoolers: an intervention study. Journal of Child Language, 26(1), 49-67.

Pine, J. M., Conti-Ramsden, G., Joseph, K. L., Lieven, E. V., \& Serratrice, L. (2008). Tense over time: testing the Agreement/Tense Omission Model as an account of the pattern of tense-marking provision in early child English. Journal of Child Language, 35(1), 55-75.

Räsänen, S. H., Ambridge, B., \& Pine, J. M. (2016). An elicited-production study of inflectional verb morphology in child Finnish. Cognitive Science, 40(7), 1704-38.

Reese, E., Leyva, D., Sparks, A., \& Grolnick, W. (2010). Maternal elaborative reminiscing increases low-income children's narrative skills relative to dialogic reading. Early Education and Development, 21(3), 318-42.

Reese, E., \& Newcombe, R. (2007). Training mothers in elaborative reminiscing enhances children's autobiographical memory and narrative. Child Development, 78(4), 1153-70.

Rezzonico, S., Hipfner-Boucher, K., Milburn, T., Weitzman, E., Greenberg, J., Pelletier, J., \& Girolametto, L. (2015). Improving preschool educators' interactive shared reading: effects of coaching in professional development. American Journal of Speech and Language Pathology, 24, 717-32.

Richman, A. L., Miller, P. M., \& LeVine, R. A. (1992). Cultural and educational variations in maternal responsiveness. Developmental Psychology, 28(4), 614-21. 
Rogoff, B. (1995). Observing sociocultural activity on three planes: participatory appropriation, guided participating, and apprenticeship. In J. V. Wertsch, P. del Rio, \& A. Alvarez (Eds.), Sociocultural studies of mind (pp. 139-64). Cambridge University Press.

Romeo, R. R., Leonard, J. A., Robinson, S. T., West, M. R., Mackey, A. P., Rowe, M. L., \& Gabrieli, J. D. (2018). Beyond the 30-million-word gap: children's conversational exposure is associated with language-related brain function. Psychological Science, 29(5), 700-10.

Roseberry, S., Hirsh-Pasek, K., \& Golinkoff, R. M. (2014). Skype me! Socially contingent interactions help toddlers learn language. Child Development, 85(3), 956-70.

Rowe, M. L. (2012). A longitudinal investigation of the role of quantity and quality of child-directed speech in vocabulary development. Child Development, 83(5), 1762-74.

Rowe, M. L. (2018). Understanding socioeconomic differences in parents' speech to children. Child Development Perspectives, 12(2), 122-7.

Rowe, M. L., \& Goldin-Meadow, S. (2009). Differences in early gesture explain SES disparities in child vocabulary size at school entry. Science, 323(5916), 951-3.

Rowe, M. L., Leech, K. A., \& Cabrera, N. (2017). Going beyond input quantity: wh-questions matter for toddlers' language and cognitive development. Cognitive Science, 41, 162-79.

Ruffman, T., Slade, L., \& Crowe, E. (2002). The relation between children's and mothers' mental state language and theory-of-mind understanding. Child Development, 73, 734-51.

Saito, Y., Aoyama, S., Kondo, T., Fukumoto, R., Konishi, N., Nakamura, K., ... Toshima, T. (2007). Frontal cerebral blood flow change associated with infant-directed speech (IDS). Archives of Disease in Childhood: Fetal and Neonatal Edition, 92, F113-F116.

Salo, V. C., Rowe, M. L., Leech, K. A., \& Cabrera, N. J. (2016). Low-income fathers' speech to toddlers during book reading versus toy play. Journal of Child Language, 43(6), 1385-99.

Schick, A. (2015). Wordless book-sharing styles in bilingual preschool classrooms and Latino children's emergent literacy skills. Journal of Early Childhood Literacy, 15, 331-63.

Schieffelin, B. B. (1990). The give and take of everyday life: language socialization of Kaluli children (No. 9). Cambridge University Press.

Schmerse, D., Lieven, E., \& Tomasello, M. (2013). Error patterns in young German children's wh-questions. Journal of Child Language, 40(3), 656-71.

Schwab, J. F., Rowe, M. L., Cabrera, N., \& Lew-Williams, C. (2018). Fathers' repetition of words is coupled with children's vocabularies. Journal of Experimental Child Psychology, 166, 437-50.

Senechal, M. (2017). Shared book reading. an informal literacy activity par excellence. In N. Kucirkova, C. Snow, V. Grøver, \& C. McBride (Eds.), The Routledge international handbook of early literacy education: a contemporary guide to literacy teaching and interventions in a global context (pp. 27382). London: Routledge.

Senechal, M., Pagan, S., Lever, R., \& Quelette, G. (2008). Relations among the frequency of shared reading and 4-year-old children's vocabulary, morphological and syntax comprehension, and narrative skills. Early Education and Development, 19, 27-44.

Shimpi, P. M., \& Huttenlocher, J. (2007). Redirective labels and early vocabulary development. Journal of Child Language, 34(4), 845-59.

Shneidman, L., Arroyo, M. E., Levine, S. C., \& Goldin-Meadow, S. (2013). What counts as effective input for word learning? Journal of Child Language, 40(3), 672-86.

Shneidman, L. A., \& Goldin-Meadow, S. (2012). Language input and acquisition in a Mayan village: How important is directed speech? Developmental Science, 15(5), 659-73.

Shonkoff, J. P., \& Bales, S. N. (2011). Science does not speak for itself: translating child development research for the public and its policymakers. Child Development, 82(1), 17-32.

Snow, C. E. (1977). The development of conversation between mothers and babies. Journal of Child Language, 4(1), 1-22.

Snow, C. E. (1972). Mothers' speech to children learning language. Child Development, 43(2), 549-65.

Snow, C. E. \& Goldfield, B. (1982). Building stories: the emergence of information structures from conversation and narrative. In D. Tannen (Ed.), Georgetown University Roundtable on Language and Linguistics 1981. Analyzing discourse: text and talk (pp. 127-41). Washington, DC: Georgetown University Press.

Snow, C. E. \& Goldfield, B. (1983). Turn the page please: situation-specific language learning. Journal of Child Language, 10, 551-70. 
Soderstrom, M. (2007). Beyond babytalk: re-evaluating the nature and content of speech input to preverbal infants. Developmental Review, 27, 501-32.

Tamis-LeMonda, C. S., \& Bornstein, M. H. (1994). Specificity in mother-toddler language-play relationships across the second year. Developmental Psychology, 30, 283-92.

Tamis-LeMonda, C. S., Kuchirko, Y., \& Song, L. (2014). Why is infant language learning facilitated by parental responsiveness? Current Directions in Psychological Science, 23(2), 121-6.

Tomasello, M., Carpenter, M., Call, J., Behne, T., \& Moll, H. (2005). Understanding and sharing intentions: the origins of cultural cognition. Behavioral and Brain Sciences, 28, 675-91.

Tomasello, M., \& Farrar, M. J. (1986). Joint attention and early language. Child Development, 57(6), 1454-63.

Uccelli, P., Demir-Lira, Ö. E., Rowe, M. L., Levine, S., \& Goldin-Meadow, S. (2019). Children's early decontextualized talk predicts academic language proficiency in midadolescence. Child Development, 90(5), 1650-63.

Vasilyeva, M., Huttenlocher, J., \& Waterfall, H. (2006). Effects of language intervention on syntactic skill levels in preschoolers. Developmental Psychology, 42(1), 164-74.

Vigil, D. C. (2002). Cultural variations in attention regulation: a comparative analysis of British and Chinese-immigrant populations. International Journal of Language \& Communication Disorders, 37 (4), 433-58.

Vygotsky, L. S. (1978). Mind in society (ed. M. Cole, V. John-Steiner, S. Scribner, \& E. Souberman). Cambridge, MA: Harvard University Press.

Wasik, B., \& Hindman, A. (2014). Understanding the active ingredients in an effective preschool vocabulary intervention: an exploratory study of teacher and child talk during book reading. Early Education and Development, 25, 1035-56.

Weisberg, D. S., Zosh, J. M., Hirsh-Pasek, K., \& Golinkoff, R. M. (2013). Talking it up: play, language development, and the role of adult support. American Journal of Play, 6(1), 39-54.

Weisleder, A., \& Fernald, A. (2013). Talking to children matters: early language experience strengthens processing and builds vocabulary. Psychological Science, 24(11), 2143-52.

Weizman, Z. O., \& Snow, C. E. (2001). Lexical input as related to children's vocabulary acquisition: effects of sophisticated exposure and support for meaning. Developmental Psychology, 37(2), 265-79.

Whitehurst, G. J., Falco, F. L., Lonigan, C. J., Fischel, J. E., DeBaryshe, B. D., Valdez-Menchaca, M. C., \& Caulfield, M. (1988). Accelerating language development through picture book reading. Developmental Psychology, 24(4), 552-9.

Yu, C., \& Smith, L. B. (2012). Embodied attention and word learning by toddlers. Cognition, 125(2), 244-62.

Zevenbergen, A. A., Whitehurst, G. J., \& Zevenbergen, J. A. (2003). Effects of a shared-reading intervention on the inclusion of evaluative devices in narratives of children from low-income families. Journal of Applied Developmental Psychology, 24(1), 1-15.

Zimmerman, F. J., Gilkerson, J., Richards, J. A., Christakis, D. A., Xu, D., Gray, S., \& Yapanel, U. (2009). Teaching by listening: the importance of adult-child conversations to language development. Pediatrics, 124(1), 342-9.

Cite this article: Rowe ML, Snow CE (2020). Analyzing input quality along three dimensions: interactive, linguistic, and conceptual. Journal of Child Language 47, 5-21. https://doi.org/10.1017/S0305000919000655 